\title{
THE EFFECT OF PARTICULATE FILLERS ON HARDNESS OF POLYMER COMPOSITE
}

\author{
Ludmila Dulebova' ${ }^{1}$, Tomasz Garbacz ${ }^{2}$ \\ 1 Technical University in Košice, Department Technologies and Materials, Faculty of Mechanical Engineering \\ 74 Mäsiarska St., 04001 Košice, Slovakia, e-mail: ludmila.dulebova@tuke.sk \\ 2 Lublin University of Technology, Mechanical Engineering Faculty, Department of Technology and Polymer \\ Processing, 36 Nadbystrzycka St., 20-618 Lublin, Poland, e-mail: t.garbacz@pollub.pl
}

Received: 2017.05.15

Accepted: 2017.07.01

Published: 2017.09.03

\begin{abstract}
The analysis of polymeric composites can be quite challenging because the samples are often of complex nature due to the presence of various groups of additives, compounding ingredients, and fillers. In this contribution, changes of hardness of Polypropylene (PP) composites during and after the exposure of materials to UV chamber and low temperatures were investigated. The particulate fillers talc and chalk in weight fraction from 10 to $50 \%$ and montmorillonite (MMT) in weight fraction $4 \%$ were used as fillers in the polypropylene matrix. The composites were mixed in the extruder while the length, diameter of screw, as well as the number of grooves in the feed zone were changed. The influence of ageing - UV radiation and low temperature was examined by change of Shore hardness after $360 \mathrm{~h}$ and $720 \mathrm{~h}$ of exposure. According to the performed tests we can conclude that the tested materials may be exposed to UV radiation and low temperature of $-20^{\circ} \mathrm{C}$ without significant changes of hardness.
\end{abstract}

Keywords: polypropylene composites, ageing effect, talc filler, chalk filler.

\section{INTRODUCTION}

Since years the structural polymer materials have been regarded as an alternative material for metals, particularly light alloys. They are often modified by the introduction of fibrous fillers, sheet as well as powder. As stated in [1, 8, 14], the content of the filler in the polymer material can lead to increased stiffness, hardness, creep resistance, the ignition and combustion resistance, tensile strength and flexural strength and increasing resistance to the action of atmospheric factors.

Study performed by R. Zaboj and T. Jachowicz et al. $[4,15]$ showed that in recent years, the lifetime of polymer materials and coatings has been extended continuously in many cases. In turn, this means that the times required for testing these materials have also increased. However, such extended testing times are very often unacceptable for economic reasons. Therefore, it is an ongoing demand for material testing technology to shorten test times. One possible method of achieving this is to employ significantly increased levels of irradiance and temperature for testing under simulated conditions in weathering instruments.

Authors Dobransky and Kmetty et al. [2, 7] highlighted that polymer materials are perhaps the most sensitive material to changes in their chemical structure by influence of external conditions, which are followed by the changes of chemical, physical-mechanical properties. Degradation processes are usually accelerated by UV light, heat, the presence of oxygen, the presence of chemicals, as well as mechanical stress. In terms of UV degradation, the polypropylene can be attacked by ultraviolet radiation, where tertiary carbon bonds in their chain structures are the centres of attack. Ultraviolet rays interact with 
these bonds to form free radicals, which then react further with oxygen in the atmosphere, producing carbonyl groups in the main chain. The exposed surfaces of products may then discolour and crack, and in extreme cases, complete product disintegration can occur.

Ageing tests of polymer material belong to the most important tests for estimating the lifetime of the product. These ageing tests of polymer material are made either in real conditions of the material use or the used conditions may simulate an artificial accelerated environment. In order to test the sensitivity to the ageing of polymer materials, it would be necessary to use the test methods that reflect particular conditions in which the finished products are used. It is also necessary to take into account the susceptibility of different types of polymer materials for various degradation mechanisms. Therefore, the choice of a test method for the degradation of the polymeric material has to consider the characteristics of the polymer and the application area of the finished product. Similar approach can be found in research studies [3, $6,9,11]$, where authors pointed to the need for testing the properties of polypropylene composites after the ageing and the effect of filler contents and particle size. As the effect on tensile strength was tested many times, we proposed to look on the change of mechanical properties from the view of Shore hardness.

Testing of the ageing effect on the properties of polymeric materials consists of comparing changes in the properties of the tested samples during the exposure period to the characteristics of untreated samples. The aim of this studies was to present the comparison of measurements of Shore hardness of polymer composites with particulate fillers, during accelerated ageing in UV chamber and a climatic chamber (after 360 hours exposure and after 720 hours of exposure) on various parameters of production of test samples.

\section{MATERIAL AND METHODS}

PP is one of the most important polyolefin's that have a wide range of applications. According to many studies like [12], there has been an increase in the use of filled PP in automotive and electrical engineering. This is mainly due to the excellent stiffness property which PP exhibits and which enables it to substitute conventional materials in demanding engineering applications.
Talc is a crystalline form of silica. It consists of layer or sheet of brucite, sandwiched between two sheets of silica. Pure talc is colourless or white, but may have a glow grey, greens or yellows. Due to the hydrophobic talc epitome easily dissolved in the polymer, e.g. PP, PE. It is a very soft mineral, prone to splitting and it can withstand temperatures up to $900^{\circ} \mathrm{C}$, as listed in $[5,13]$.

Calcium Carbonate is one of the most widely used fillers which may be used in the processing of polymers. It is slightly soluble in water, readily in acid with evolution of carbon dioxide, and it is insoluble in alkali. Chalk dissociates calcium oxide, called quicklime a temperature of $850^{\circ} \mathrm{C}$. It is obtained by the dry process, wet or extracts as a mineral, commonly known as chalk, which after milling may also be used as a filler. Chalk, due to the nature of the surface and a small enhancing effect, is one of the so-called inactive fillers, as stated in references $[10,13]$.

\section{EXPERIMENTAL PROCEDURE}

As an experimental material, PP J400 filled with particulate fillers was tested. The following fillers were used: talc manufactured by company Bodo Möller Chemie, the particulate size was from $0.15 \mu \mathrm{m}$ to $0.40 \mu \mathrm{m}$ and chalk manufactured by company Washington Penn Plastic, Co., particulate size was from $0.75 \mu \mathrm{m}$ to $1.25 \mu \mathrm{m}$. The weight fraction of used fillers in PP for studies were: chalk (K) from $10 \%$ to $50 \%$, talc (T) from $10 \%$ to $40 \%$ and montmorillonite (MMT) was 4 wt. $\%$.

Plasticization of PP composites were made in a plasticizing system of laboratory extruder. The composites were prepared using the variable length $\mathrm{L}$ of the extrusion process, at a constant an external diameter $\mathrm{D}$ of the screw $(\mathrm{D}=$ $25 \mathrm{~mm}$ ). The quotient of L / D of screw were 20, 25 and 30. For experiments were used a variable number of grooves from 0 to 4 in the feed zone of plasticizing system.

The experimental samples - rectangle cross section $20 \times 2 \mathrm{~mm}$ with length of $100 \mathrm{~mm}$ were made by extrusion process and they were exposed to different climatic conditions. A half of samples were exposed to the effects of ultraviolet radiation by intensity $4 \times 18 \mathrm{~W}$ into UV chamber. The samples were irradiated continuously for 12 hours, followed by a 12 hour interval for a period 720 hours. The second part of the samples were placed in an environmental chamber Thermotron SM-1.2-3200 at $-20^{\circ} \mathrm{C} \pm 3^{\circ} \mathrm{C}$ for a period of 720 hours. 


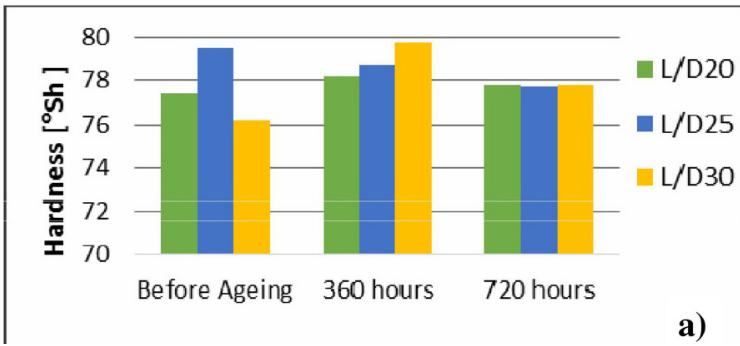

a)
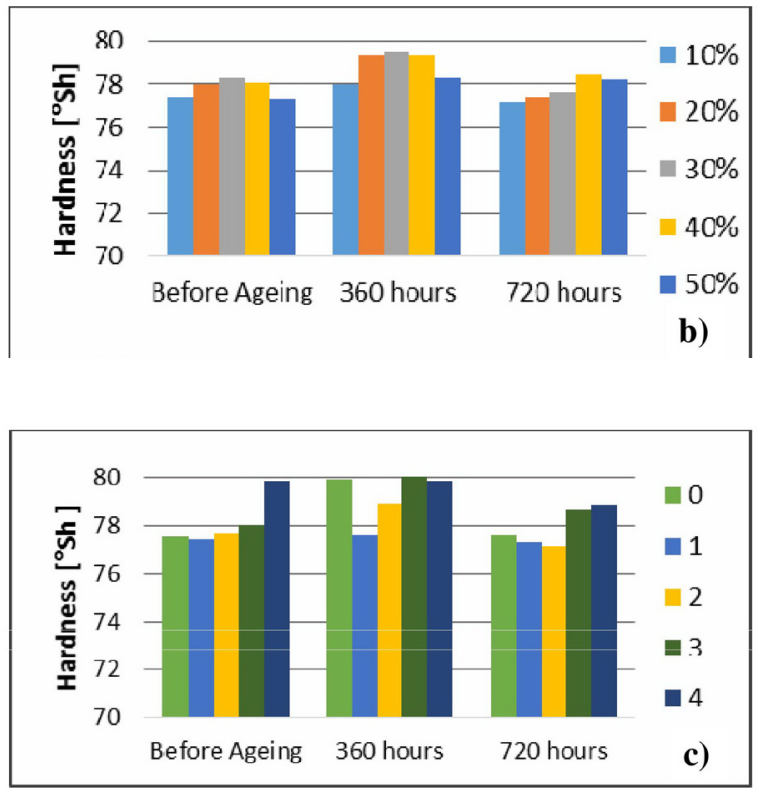

Fig. 1. Shore Hardness of composite PP/chalk (UV chamber): a) L/D of screw, b) wt. \% filler, c) number of grooves

Hardness of samples was measured according to STN EN ISO 868. Hardness measurement was performed before the period of exposure to the climatic conditions as well as after 360 hours and 720 hours on all samples. Five samples were produced for every type of material and on the each sample, five measurements were performed. For hardness measurements portable hardness tester Mitutoyo HardmaticHH-300 was used and testing was performed according to ISO 868 , method Shore type D (needle pin steel rod).

\section{ACHIEVED RESULTS}

The average hardness values from 20 measurements on 5 samples from each material after extrusion and after ageing in UV chamber depending on the concentration of fillers, number of grooves and the ratio L/D of screw are shown on Fig. 1 and Fig. 2.

In Figures 1 and 2 we can see that 720 hours of ageing by UV radiation had no significant effect on hardness for each type of sample (samples
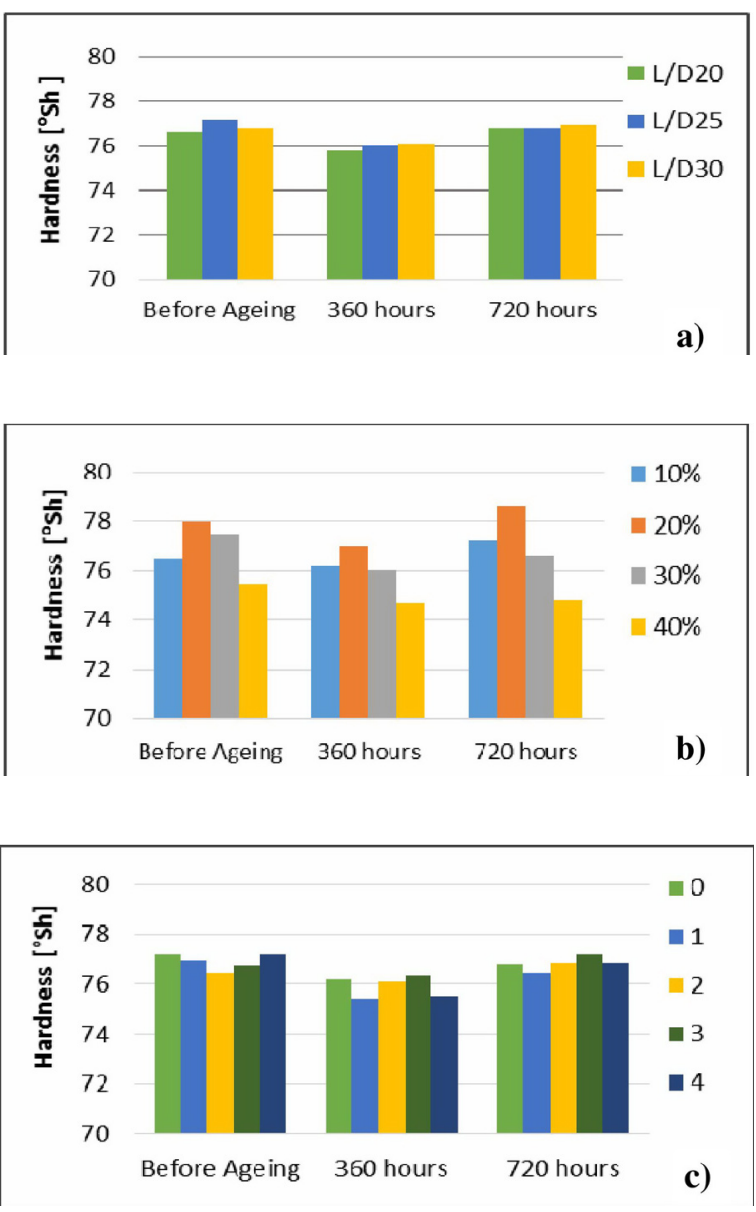

Fig. 2. Shore Hardness of composite PP/talc (UV chamber): a) L/D of screw, b) wt. \% filler, c) number of grooves

with different concentration of fillers, number of grooves and the L/D ratio of screw). Lightly increased values of hardness ( 1 to $\left.2^{\circ} \mathrm{Sh}\right)$ were measured at PP/chalk after 360 hours of ageing. On the other side, slightly decreased hardness $\left(1^{\circ} \mathrm{Sh}\right)$ was observed at PP/talc composite after same 360 hours of ageing. From Figure 1 we can conclude that the average value of the hardness at $\mathrm{PP} /$ chalk composite produces with different screws (different number of grooves in the feed zone of the extruder) has the highest variance after 360 hours ageing with slightly decreased hardness (1-2 $\left.{ }^{\circ} \mathrm{Sh}\right)$. Hardness of PP/talc composites with different extrusion setup and amount of the filler has changed minimum after the ageing (less than $1^{\circ} \mathrm{Sh}$ ).

Average hardness values of PP composites after the production and after the ageing at low temperature $\left(-20^{\circ} \mathrm{C}\right)$ in dependence to the number of grooves of the screw, concentration of the filler and L/D ration are shown in Figure 3 and Figure 4.

In Figure 3 and Figure 4 we can see a slight decrease of hardness after low temperature ageing af- 

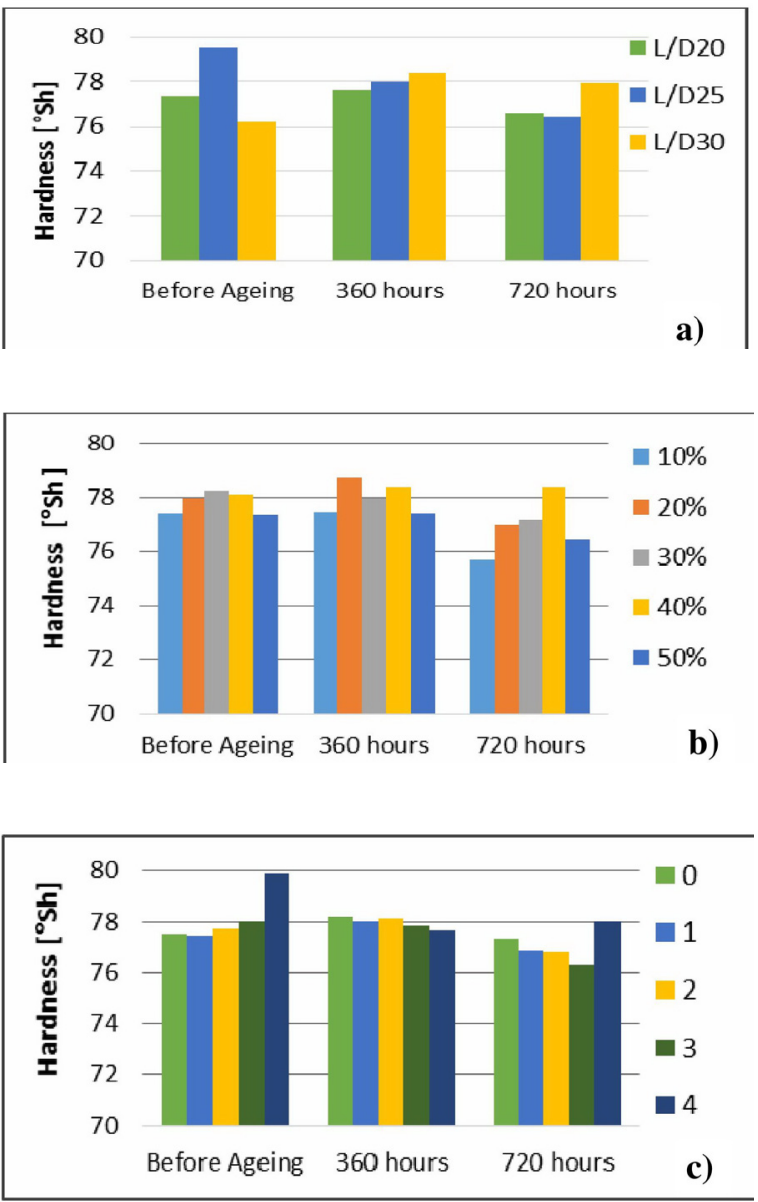

Fig. 3. Shore Hardness of composite PP/chalk (- 20 $\left.{ }^{\circ} \mathrm{C}\right)$ : a) L/D ratio of screw, b) wt. \% filler, c) number of grooves

ter 360 and 720 hours. The decrease of the hardness is in the range $1-2^{\circ} \mathrm{Sh}$, what is a negligible amount. At $\mathrm{PP} /$ chalk composite at produced with $\mathrm{L} / \mathrm{D}$ ratio of 30 , minor increase of hardness $\left(2^{\circ} \mathrm{Sh}\right)$ after 720 hours of ageing in low temperature was observed. Measured hardness Shore D at PP/talk composite after ageing was lower in comparison to original value for every different number of grooves setup, maximum difference at 4 grooves screw $\left(2,7^{\circ} \mathrm{Sh}\right)$ and least for two grooves setup $\left(0,7^{\circ} \mathrm{Sh}\right)$.
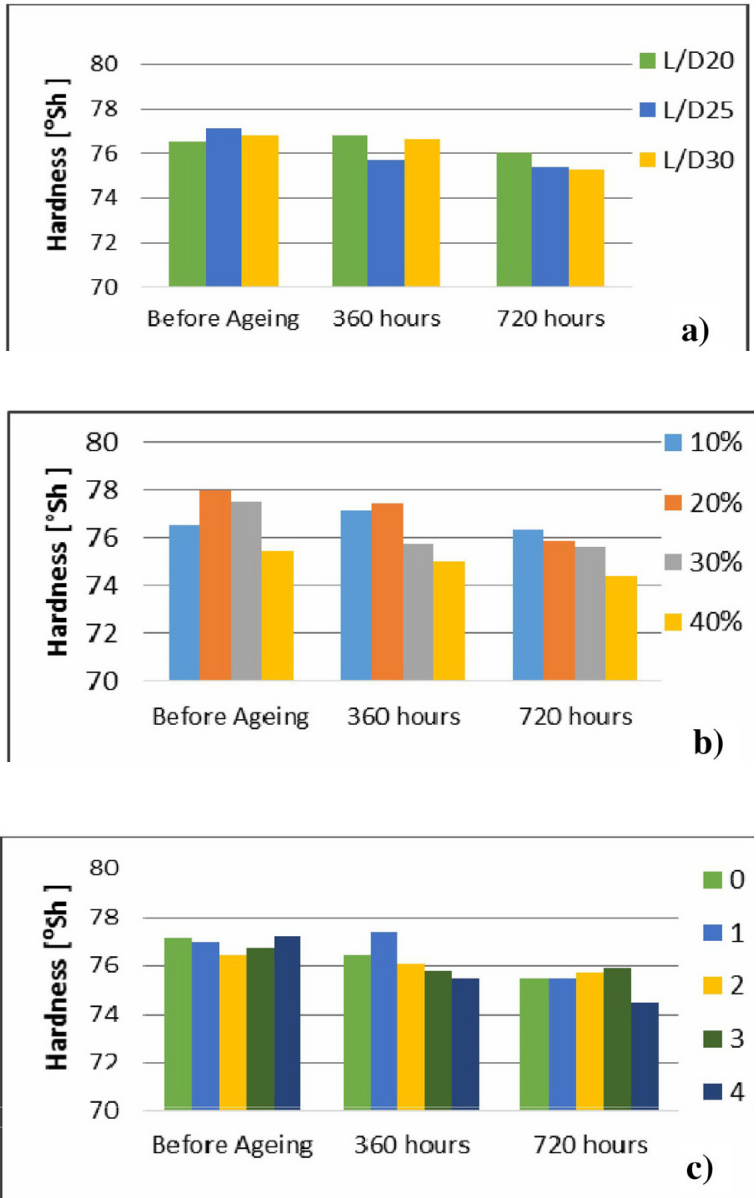

Fig. 4. Shore Hardness of composite PP/ talc (- 20 $\left.{ }^{\circ} \mathrm{C}\right):$ a) L/D of screw, b) wt. \% filler, c) number of grooves

Montmorillonite composites showed a decrease of Shore D hardness after ageing in UV chamber and at $-20^{\circ} \mathrm{C}$ (Table 1 and Table 2). With the number of grooves increases also the hardness of the composite (average increase 1-2 ${ }^{\circ} \mathrm{ShD}$ ).

Structure of tested composites was observed on microscope FEI Phenom G2 Pro. Structure of $\mathrm{PP} /$ talc composite with $40 \mathrm{wt}$. \% of filler is shown on Figure 5. The more uniform dispersion of the filler in the composite was noted at the ex-

Table 1. Shore D hardness of composite PP /4\% MMT (UV chamber)

\begin{tabular}{|c|c|c|c|c|c|c|}
\hline \multirow{2}{*}{ Grooves } & \multicolumn{2}{|c|}{ Origin composite } & \multicolumn{4}{|c|}{ UV chamber } \\
\cline { 2 - 7 } & \multicolumn{2}{|c|}{ Before Ageing } & \multicolumn{2}{|c|}{360 hours } & \multicolumn{2}{c|}{720 hours } \\
\cline { 2 - 7 } & L/D 20 & L/D 30 & L/D 20 & L/D 30 & L/D 20 & L/D 30 \\
\hline 0 & 75.3 & 74.2 & 74.7 & 76.8 & 72.8 & 73.5 \\
\hline 1 & 75.1 & 75.1 & 75.2 & 73.8 & 74.8 & 76.2 \\
\hline 2 & 74.3 & 76.1 & 72.7 & 73.4 & 75.3 & 73.9 \\
\hline 3 & 76.0 & 75.3 & 75.2 & 74.6 & 74.5 & 76.6 \\
\hline
\end{tabular}


Table 2. Shore D hardness of composites PP/ $4 \% \operatorname{MMT}\left(-20^{\circ} \mathrm{C}\right)$

\begin{tabular}{|c|c|c|c|c|c|c|}
\hline \multirow{2}{*}{ Grooves } & \multicolumn{2}{|c|}{ Origin composite } & \multicolumn{4}{|c|}{$-20^{\circ} \mathrm{C}$} \\
\cline { 2 - 7 } & \multicolumn{2}{|c|}{ Before Ageing } & \multicolumn{2}{|c|}{360 hours } & \multicolumn{2}{c|}{720 hours } \\
\cline { 2 - 7 } & L/D 20 & L/D 30 & L/D 20 & L/D 30 & L/D 20 & L/D 30 \\
\hline 0 & 75.3 & 74.2 & 74.8 & 76.8 & 74.3 & 77.0 \\
\hline 1 & 75.1 & 75.1 & 73.7 & 76.1 & 71.4 & 76.2 \\
\hline 2 & 74.3 & 76.1 & 73.6 & 75.7 & 71.0 & 75.8 \\
\hline 3 & 76.0 & 75.3 & 73.6 & 73.6 & 72.6 & 74.2 \\
\hline
\end{tabular}
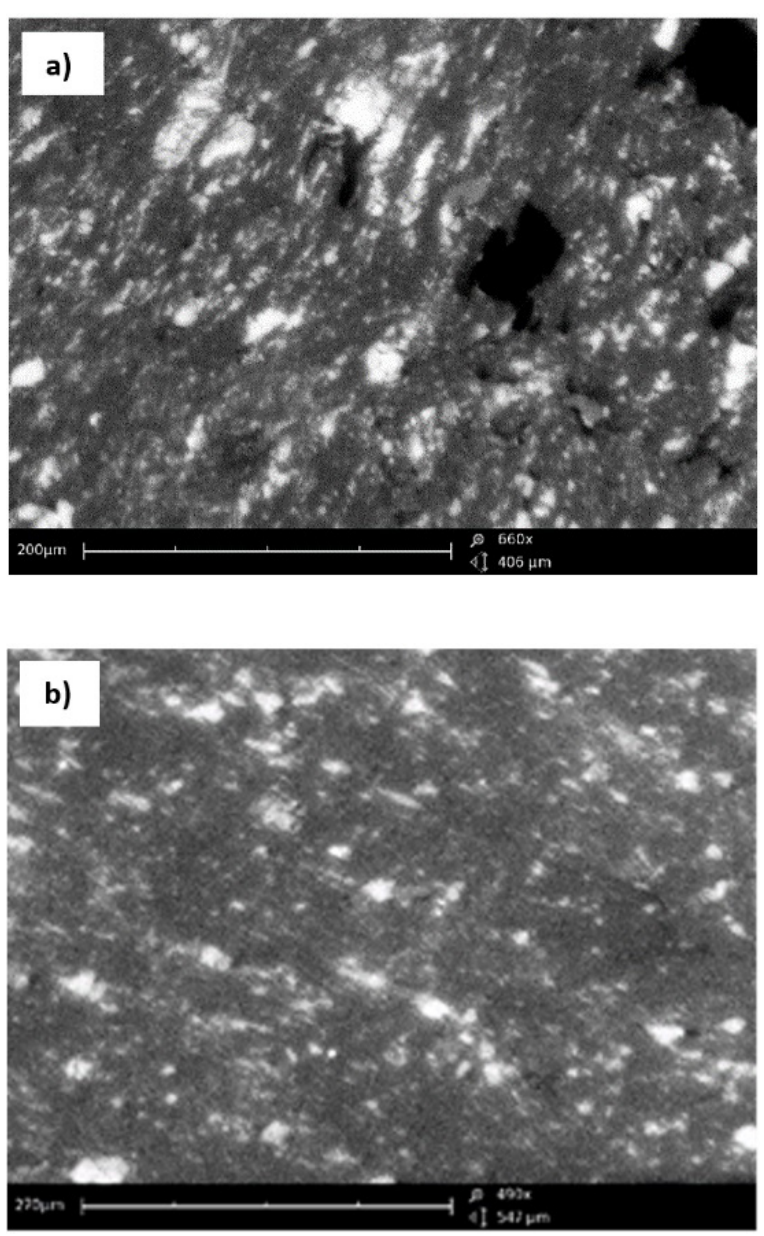

Fig. 5. Structure PP/ 40 wt.\% talc extrused by grooves number 1 a) L/D20 and b) L/D30 tended flow path of the material in the screw plasticizing system, resulting in better mixing of the components in the composite structure.

Changes in the Raman's spectras were studied before and after the ageing by Raman spectroscope ReporterTM DeltaNu. Ageing process had only a small influence on the spectras, what we can also see at characteristic absorption peaks. At a higher L/D ratio composites showed a slightly increase of peaks regardless the production and ageing conditions (UV radiation, low temperature $-20^{\circ} \mathrm{C}$ ). These changes for PP/talk composite are shown on Fig. 6. Change of the number of screws grooves and path legth of screw does not impact on Raman spectra peaks, greater impact was reflected with the increasing ammount of filler in the matrix.

\section{CONCLUSIONS}

The aim of this paper was to investigate the effects of changing a certain amount of particulate filler (chalk, talk, MMT) on the hardness of the composite with PP matrix. The hardness of particulate filled PP increased with increasing amount of filler content, L/D ratio of screw and number of grooves. In addition to this base measurements, impact of ageing (UV radiation and low temperature $-20^{\circ} \mathrm{C}$ ) for 360 and 720 hours was investigated. Examination of structure con-

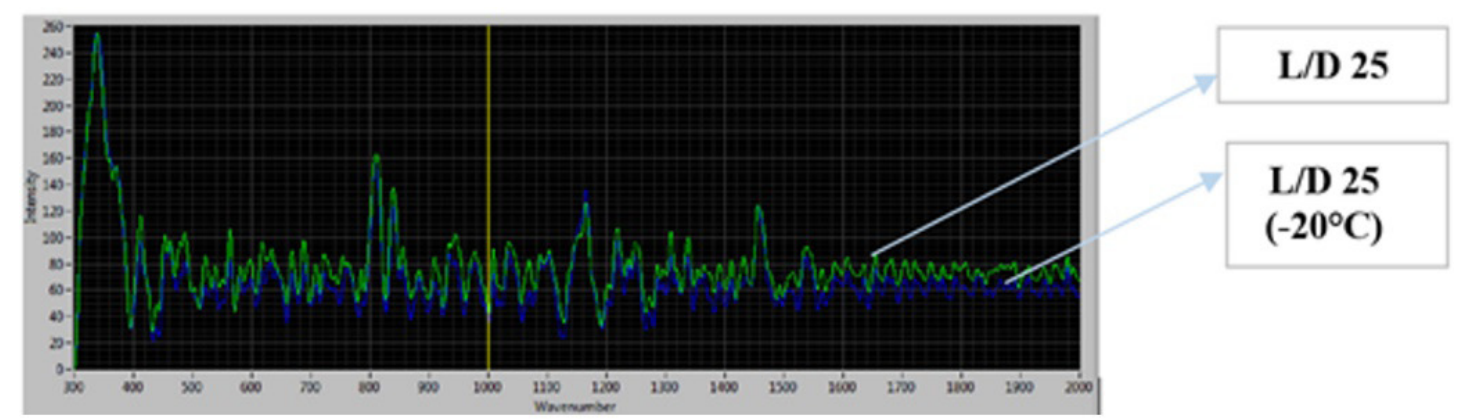

Fig. 6. Raman spectroscopy of composite PP/talc 20 wt. \%, grooves number 1 
firmed that the change of screw length positively influence on the distribution of the filler. The path length had no significant effect on the hardness of the tested composites.

Changes of hardness were observed at PP/ chalk composites with changing $\mathrm{L} / \mathrm{D}$ ratio of screw before the ageing. Decrease of hardness of PP/talk composites was observed after 360 hours of ageing in UV chamber. The difference of the measured values was minimal (1-3 $\left.{ }^{\circ} \mathrm{Sh}\right)$. Montmorillonite composites showed a minimal decrease of hardness after ageing. Also changes of the number of grooves and L/D ratio had minimal effect on the final value of hardness. Correlation has not been found between the hardness of composites with MMT and extrusion parameters. Influence of the UV and low temperature ageing was minimal for composites with PP matrix and talk, chalk and MMT fillers.

According to the tests carried out we can conclude that products made from the tested material may be exposed to UV radiation and low temperature of $-20^{\circ} \mathrm{C}$ without significant changes of hardness and may be therefore exposed to the external environment.

\section{Acknowledgements}

This paper is the result of the project implementation KEGA 059 TUKE-4/2016.

\section{REFERENCES}

1. Běhálek L., Dobránsky J. Conformal cooling of the injection moulds. Applied Mechanics and Materials, 308, 2013, 127-132.

2. Dobránsky J., Běhálek L., Baron P. Gate location and its impact to flowing characteristics of plastic moldings. Key Engineering Materials, 669, 2016, 36-43.

3. Garbacz T. Structure and properties of cellular thin-walled cable coatings. Polimery, 57 (11-12), 2012, 91-94.

4. Jachowicz T., Garbacz T., Tor-Swiatek A. et al. Investigation of Selected Properties of InjectionMolded Parts Subjected to Natural Aging. International Journal of Polymer Analysis and Characterization, 20 (4), 2015, 307-315.
5. Jeziorska R., Klepka T., Paukszta D. Polycarbonate/maleic anhydride grafted polyethylene/graphite composites. Polimery, 52 (4), 2007, 294-298.

6. Klepka T., Nabiałek J. Analysis of forming geometrical macrostructure in walls of extrusion products manufactured from polypropylene composite filled with $\mathrm{CaCO}_{3}$. Kompozyty, 2011, 3, 274-277.

7. Kmetty A., Tabi T., Kovacs J. G. et al. Development and characterization of injection moulded, all-polypropylene composites. Express Polymer Letters, 7 (2), 2013, 134-145.

8. Leong Y. W., Abu Bakar M. B., Mohd Z. A..Ishak, A. Ariffin and Pukanszky B. Comparison of the Mechanical Properties and Interfacial Interactions between Talc, Kaolin and Calcium Carbonate Filled Polypropylene Composites. Journal of Applied Polymer Science, 91 (5), 2004, 3315-3326.

9. Navratil J., Maňas M., Stanek M. et al. Hardness/ microhardness properties of HDPE blends. Key Engineering Materials, 662, 2015, 181-184.

10. Onuegbu G. C., Igwe I. O. The effects of filler contents and particle size on the mechanical and enduse properties of snail shell powder filled polypropylene. Materials Science and Application, 31(2), 2011, 811-817.

11. Tavares A.C., Gulmine J.V., Lepienski C.M., Akcelrud $\mathrm{L}$. The effect of accelerated ageing on the surface mechanical properties of polyethylene. Polymer Degradation and Stability, 81 (2), 2003, 367-373.

12. Tor-Świątek A., Garbacz T., Jachowicz T. Quantitative assessment of the microscopic structure of extruded and injected low-density polyethylene modified with micro-spheres by image analysis. Cellular Polymers, 35 (2), 2016, 67-84.

13. Tor-Świątek A. Evaluation of the effectiveness of the microcellular extrusion process of low density polyethylene. Eksploatacja i niezawodnośćMaintenance and reliability, 15 (3), 2013, 225-229.

14. Woo L., Ling M., Khare A.R., Ding Y. S., Polypropylene degradation and durability estimates based on the master curve concept. Ed. L. Mallinson: Ageing Studies and Lifetime Extension of Materials. Kluwer Academic/Plenum Publishers, New York, 2001, 499-506.

15. Záboj R., Influence of process conditions on the local shrinkage and on the pressure evolution inside the mold cavity of the injection molded polypropylene in two modifications - PP homopolymer; $40 \%$ talc filled PP, Key Engineering Materials, 669, 2016, 11-18. 